\title{
Safety of MR-guided focused ultrasound treatment of pedunculated subserosal uterine leiomyomas
}

\author{
Douglas L Brown ${ }^{1 *}$, Gina K Hesley ${ }^{1}$, Krzysztof R Gorny ${ }^{1}$ and Elizabeth A Stewart ${ }^{2}$
}

\begin{abstract}
Background: There has previously been a concern about whether it is safe to use minimally invasive methods to treat pedunculated subserosal uterine leiomyomas. The purpose of our study is to evaluate the safety of magnetic resonance-guided focused ultrasound (MRgFUS) ablation of pedunculated subserosal uterine leiomyomas.

Methods: All cases of MRgFUS ablations performed at our institution from March 2005 through March 2010 were reviewed to identify patients in whom a pedunculated subserosal leiomyoma was treated. Follow-up clinical and surgical data were reviewed to assess for complications.

Results: A pedunculated leiomyoma was treated in 11 of 179 patients. Only two of the 11 patients had complications, both of which were minor and likely unrelated specifically to the pedunculated leiomyomas. One patient had transient lumbar plexopathy contralateral to the pedunculated leiomyoma, and one patient had transient voiding difficulty. Operative findings in three other patients who subsequently had myomectomy or hysterectomy found no adhesions or other complications related to the pedunculated leiomyomas.
\end{abstract}

Conclusions: Pedunculated subserosal leiomyomas are not a contraindication to treatment by MRgFUS. We found no evidence of complications specifically related to pedunculated subserosal leiomyomas.

Keywords: Ablation, Ultrasound, Uterus, Magnetic resonance, Safety, Pedunculated leiomyoma

\section{Background}

Magnetic resonance-guided focused ultrasound (MRgFUS) is becoming a more frequently used minimally invasive method for the treatment of uterine leiomyomas [1-3]. In October 2004, the MRgFUS device ExAblate ${ }^{\circ} 2000$ (InSightec, Haifa, Israel) was approved by the United States Food and Drug Administration (FDA) for the treatment of uterine leiomyomas. This treatment method allows another option for patients, in addition to the more widely available minimally invasive method of uterine artery embolization (UAE), and more traditional surgical methods of myomectomy and hysterectomy.

Pedunculated leiomyomas were initially considered a relative contraindication to treatment by UAE [4]. This was based on the concern that such leiomyomas might undergo torsion or detach after treatment and cause complications such as sepsis or bowel injury that would require surgery [5-7]. However, more recent studies suggest

\footnotetext{
* Correspondence: brown.douglas@mayo.edu

'Department of Radiology, Mayo Clinic, 200 First Street SW, Rochester, MN 55905, USA

Full list of author information is available at the end of the article
}

that UAE of pedunculated subserosal leiomyomas may be safely performed [6-8].

Though the mechanisms of treatment are different for UAE and MRgFUS ablation, there has still been some concern about whether it is safe to treat pedunculated subserosal leiomyomas with MRgFUS. As the thermal energy from ultrasound extends outside the focal zone, it is conceivable that treating a leiomyoma at the serosal surface of the uterus could also injure adjacent structures. A survey of physicians performing MRgFUS found moderate concern for treating pedunculated subserosal leiomyomas [9]. The purpose of our study is to evaluate the frequency of complications in patients who had MRgFUS ablation of pedunculated subserosal uterine leiomyomas.

\section{Methods}

Our institution has been performing MRgFUS ablation of uterine leiomyomas in patients with clinical indications for treatment since March 2005 [10-13]. A database of all treated patients has been kept for retrospective research purposes such as this one, with approval by the Mayo

\section{Biomed Central}


Clinic Institutional Review Board. The MRgFUS treatments were performed using an ExAblate 2000 (InSightec Inc., Haifa, Israel) MRgFUS device integrated with a General Electric Signa (GE Healthcare, Waukesha, WI, USA) $1.5-\mathrm{T}$ magnetic resonance (MR) scanner. The method of treatment has been described previously [11], and the treatment method for pedunculated subserosal leiomyomas was the same as for leiomyomas in other locations. While the stalk may have been included in occasional sonications, we did not attempt to ablate the stalk. This report reviews all patients treated at our institution from March 2005 (when we began performing clinical treatments at our institution) through March 2010. Images of MR exams for all treated patients were reviewed to identify those in whom a pedunculated subserosal uterine leiomyoma was treated with MRgFUS. Patients who denied consent for the use of their medical information for research purposes were excluded from the study. We only included patients in whom sonications were placed within a pedunculated subserosal leiomyoma.
The MR exams of identified patients were reviewed and the uterine leiomyomas were evaluated by a radiologist who performs these treatments to confirm that a pedunculated subserosal leiomyoma was treated with MRgFUS (Figure 1). Following the reporting standards used for UAE, we defined a pedunculated subserosal leiomyoma as one in which the leiomyoma has its center outside the uterus and is attached to the uterus by a stalk narrower than $50 \%$ of the diameter of the leiomyoma [14]. The pedunculated leiomyoma was measured on T2weighted images, using sagittal, coronal, and transverse plane images. The largest leiomyoma diameter was first identified and measured, followed by the two orthogonal measurements. In our experience, we felt the stalk was generally best seen on T1-weighted images after intravenous administration of gadolinium. Stalk measurements were made by reviewing sagittal, coronal, and transverse plane images after gadolinium administration to identify and measure the stalk. We used the smallest stalk diameter and largest leiomyoma diameter. If more than one pedunculated leiomyoma was treated, the largest was used
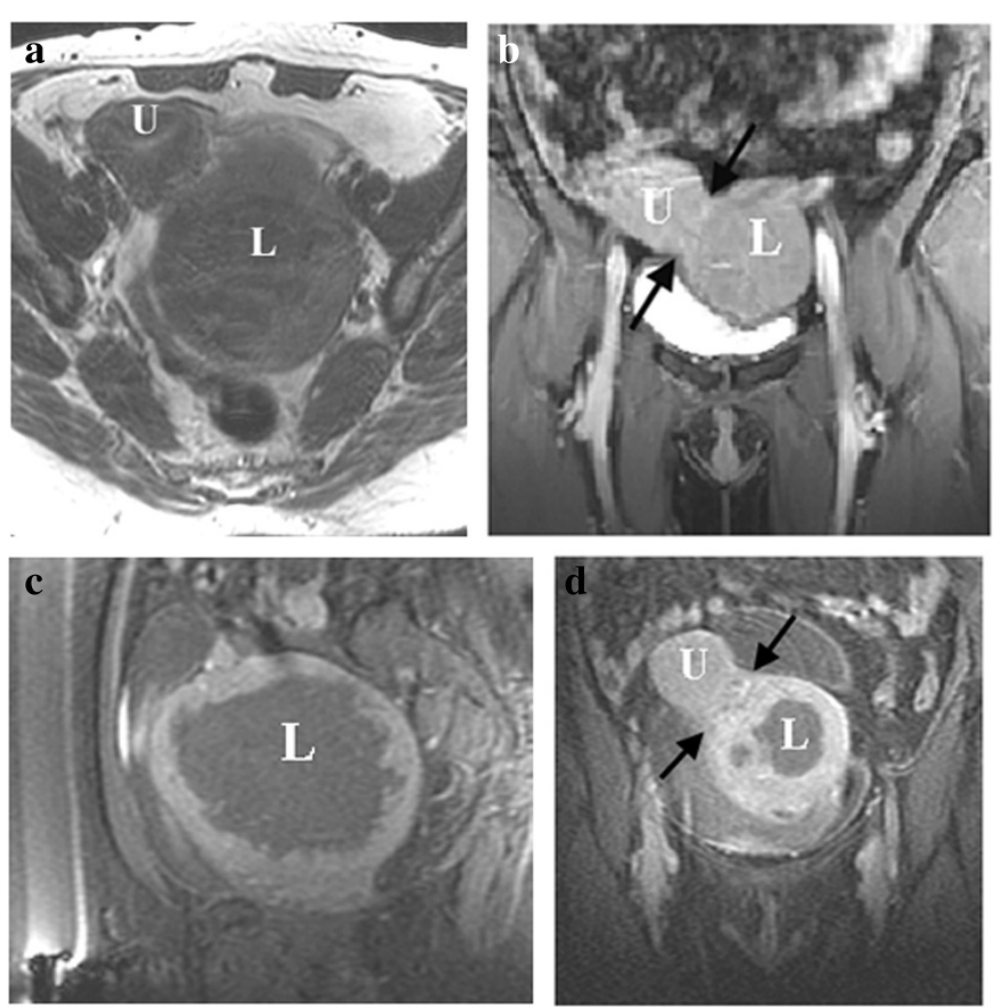

Figure 1 Fifty-one-year-old woman with pedunculated subserosal leiomyoma treated by MR-guided focused ultrasound ablation.

(a) Axial T2-weighted image before treatment shows a pedunculated leiomyoma $(\mathrm{L})$ measuring $11.7 \mathrm{~cm}$ in greatest dimension, located along the left lateral aspect of the uterus $(U)$. (b) Coronal T1-weighted image with fat suppression after intravenous gadolinium contrast agent; before treatment, shows the stalk (between arrows) connecting the pedunculated leiomyoma $(\mathrm{L})$ to the uterus $(\mathrm{U})$. The stalk diameter measured $3.6 \mathrm{~cm}$. (c) Sagittal T1-weighted image with fat suppression after intravenous gadolinium contrast agent, immediately following focused ultrasound ablation, shows large area of non-enhancement within the pedunculated leiomyoma (L). (d) Coronal T1-weighted image with fat suppression after intravenous gadolinium contrast agent, immediately following focused ultrasound ablation, shows part of the area of non-enhancement within the pedunculated leiomyoma (L). The stalk (between arrows) connecting the leiomyoma to the uterus $(U)$ remains perfused. 
for reporting purposes. The pretreatment screening MR was used for evaluation unless the interval from screening to treatment was greater than 6 months. If the interval was longer than 6 months, the MR images on the day of treatment were used to assess the leiomyoma and the stalk.

We routinely attempt to contact patients by phone at $3,6,12,24,36$, and 60 months following their MRgFUS treatment to assess symptom relief, complications, and whether additional procedures had been performed. Consistent phone contact with each patient at each interval up to 60 months was often difficult to achieve, and data were not available for each patient at every time point. Immediate posttreatment images and any available medical records were reviewed to identify unreported treatments and complications. Complications were graded as major or minor based on previously published definitions used to report complications for UAE [14]. If patients had pelvic surgery after MRgFUS ablation, the operative note was reviewed to evaluate for the presence of adhesions or other complications.

The non-perfused volume (NPV) of the leiomyoma was calculated using immediate posttreatment images after gadolinium contrast agent. The largest dimension of the area of non-enhancement in the leiomyoma was first identified and measured, followed by measurement of the two orthogonal dimensions. The three dimensions (in centimeters) were multiplied together then multiplied by 0.52 to determine the NPV (in cubic centimeters).

\section{Results}

During the time period of the study, we performed MRgFUS ablations for leiomyomas on 182 patients. Three patients who denied consent for the use of their information for research purposes were excluded from the study. Of the remaining 179 patients, 11 patients had at least one pedunculated subserosal leiomyoma that was treated with MRgFUS and constitute the study group (Table 1). The mean stalk diameter in our patients was $3.4 \mathrm{~cm}$, with a range of 1.6 to $5.1 \mathrm{~cm}$. The mean stalk diameter to leiomyoma diameter ratio was 0.36 , with a range of 0.16 to 0.48 . The stalk remained perfused after the MRgFUS ablation in all patients.

Of the 11 patients, nine had no complications and two had minor complications (Table 1). Patient number 8 had treatment of three leiomyomas: a left pedunculated subserosal leiomyoma and two right intramural leiomyomas. Post procedure, she developed a right lumbar plexopathy, with pain, numbness, and weakness in the L4-5 distribution of the right leg. This was resolved within 3 months after treatment.

Patient number 9 was able to void initially after treatment (after the Foley catheter was removed) but was presented to the Emergency Department 16 hours after
MRgFUS treatment of a single leiomyoma with inability to void. A Foley catheter was placed, which returned $750 \mathrm{~cm}^{3}$ of urine. The Foley catheter was then removed and the patient was later able to void normally. There was no recurrence of voiding difficulty during the 15 months of available follow-up. The treating emergency room physician was uncertain whether the voiding difficulty was related to the leiomyoma, the MRgFUS treatment, or medications used for moderate sedation during the MRgFUS procedure.

Of the 11 patients, four had subsequent alternative treatments for their uterine leiomyomas. Patient number 2 had three pedunculated subserosal leiomyomas that were treated with MRgFUS. The same three pedunculated subserosal leiomyomas had been treated 2 years previously with MRgFUS, as part of a separate research study before FDA approval. Three months after the MRgFUS ablation that was part of this study, she elected to have a myomectomy because her symptoms had not improved. The patient had moved elsewhere by the time of her myomectomy and the operative note was not available.

Patient number 3 had a myomectomy 45 months after her MRgFUS treatment due to non-resolution of symptoms. At surgery, she had removal of multiple leiomyomas, a diagnosis of stage I endometriosis, and no evidence of adhesions or other complications related to pedunculated subserosal leiomyomas.

Patients number 4 and 6 underwent myomectomy 46 and 15 months after MRgFUS ablation, respectively. In both patients, myomectomy was performed due to nonresolution of symptoms. At surgery, neither patient had evidence of adhesions nor other complications related to pedunculated subserosal leiomyomas.

\section{Discussion}

There was initial concern that patients undergoing minimally invasive methods of treatment of pedunculated subserosal uterine leiomyomas might be at risk for complications specific to leiomyomas of this location. This concern was first expressed related to UAE and was based on speculation that such leiomyomas might undergo torsion or detach after treatment and cause complications such as sepsis or bowel injury that could require surgery [5-7]. More recent studies suggest that UAE of pedunculated subserosal leiomyomas may be safely performed [6-8]. In one study, the authors did not perform UAE treatment if the stalk diameter was less than $2 \mathrm{~cm} \mathrm{[6];} \mathrm{however,} \mathrm{we} \mathrm{are} \mathrm{not}$ aware of any empirical data to confirm that $2 \mathrm{~cm}$ is a useful threshold for treatment decisions. While the mechanism of treatment is different for UAE and MRgFUS ablation, there has still been some concern about whether it is safe to treat pedunculated subserosal leiomyomas with MRgFUS [9]. 
Table 1 Summary of patient data

\begin{tabular}{|c|c|c|c|c|c|c|c|c|c|c|c|c|}
\hline \multirow{2}{*}{$\begin{array}{l}\text { Patient } \\
\text { number }\end{array}$} & \multirow{2}{*}{$\begin{array}{c}\text { Age } \\
\text { (years) }\end{array}$} & \multicolumn{4}{|c|}{ Treated pedunculated leiomyoma } & \multicolumn{2}{|l|}{ Stalk } & \multicolumn{2}{|c|}{ Number of leiomyomas treated } & \multirow[t]{2}{*}{ Complications } & \multirow{2}{*}{$\begin{array}{l}\text { Alternative } \\
\text { treatment }\end{array}$} & \multirow{2}{*}{$\begin{array}{r}\text { Follow-up } \\
\text { (months) }\end{array}$} \\
\hline & & Largest diameter $(\mathrm{cm})$ & Volume $\left(\mathrm{cm}^{3}\right)$ & $\operatorname{NPV}\left(\mathrm{cm}^{3}\right)$ & NPV/LV & Diameter (cm) & $\overline{S D / L D}$ & Total & Pedunculated & & & \\
\hline 1 & 47 & 10.6 & 477 & 122 & 0.26 & 5.1 & 0.48 & 4 & 1 & No & No & 36 \\
\hline 2 & 39 & 8 & 170 & 73 & 0.43 & 3.7 & 0.46 & 4 & 3 & No & Yes & 3 \\
\hline 3 & 37 & 13 & 351 & 60 & 0.17 & 3.5 & 0.27 & 8 & 1 & No & Yes & 45 \\
\hline 4 & 46 & 10.4 & 370 & 102 & 0.28 & 2.7 & 0.26 & 3 & 1 & No & Yes & 46 \\
\hline 5 & 40 & 5.9 & 83 & 15 & 0.19 & 1.8 & 0.31 & 1 & 1 & No & No & 26 \\
\hline 6 & 33 & 11 & 478 & 196 & 0.41 & 4.8 & 0.44 & 2 & 1 & No & Yes & 16 \\
\hline 7 & 52 & 11.5 & 522 & 218 & 0.42 & 3.9 & 0.34 & 1 & 1 & No & No & 36 \\
\hline 8 & 41 & 6.9 & 105 & 16 & 0.16 & 3.3 & 0.48 & 3 & 1 & Yes & No & 14 \\
\hline 9 & 51 & 11.7 & 645 & 523 & 0.81 & 3.6 & 0.31 & 1 & 1 & Yes & No & 15 \\
\hline 10 & 35 & 11 & 482 & 215 & 0.45 & 3.9 & 0.35 & 1 & 1 & No & No & 14 \\
\hline 11 & 47 & 9.9 & 376 & 23 & 0.06 & 1.6 & 0.16 & 2 & 1 & No & No & 4 \\
\hline Average & 42.5 & 10 & 369 & 142 & 0.33 & 3.4 & 0.36 & 2.7 & 1.2 & - & - & 23.2 \\
\hline Minimum & 33 & 5.9 & 83 & 15 & 0.06 & 1.6 & 0.16 & 1 & 1 & - & - & 3 \\
\hline Maximum & 52 & 13 & 645 & 523 & 0.81 & 5.1 & 0.48 & 8 & 3 & - & - & 46 \\
\hline
\end{tabular}

Abbreviations: $\mathrm{cm}$, centimeters; $\mathrm{cm}^{3}$, cubic centimeters; NPV, non-perfused volume; LV, leiomyoma volume; SD, stalk diameter; LD, leiomyoma diameter. Age is at the time of FUS treatment. Follow-up is the duration of clinical follow-up that was available. 
We found no evidence of complications specifically due to the treatment of pedunculated subserosal leiomyomas. While two patients had minor complications, we think it is unlikely that these complications were due specifically to the pedunculated subserosal leiomyomas, and more likely were minor complications of MRgFUS ablation in general that could occur with treatment of leiomyomas in any location [15]. In one patient, the treated pedunculated leiomyoma was contralateral to the side of lumbar plexopathy. This complication was likely related to the treatment of the two intramural fibroids on the same side as the plexopathy. The other patient had transient difficulty with voiding, likely related to the procedure in general and possibly to the narcotic medications used during the treatment. Additionally, of the four patients who had surgery after MRgFUS, three had operative notes available and none had evidence of adhesions or other complications. We are aware of only one other study that has evaluated for complications after MRgFUS of pedunculated subserosal leiomyomas and our results are in agreement [16]. In that study of nine patients, no adverse events were found during 6 months of follow-up after the treatment of a pedunculated leiomyoma.

Limitations of our study include its retrospective nature and relatively small number of patients. Our study does not allow us to assess whether there is a threshold for stalk diameter below which the risk of complications might change. Two of our patients had a stalk diameter below the 2-cm cutoff suggested in a study of UAE patients [6], and neither patient had a complication. It is also possible that a low NPV in some patients was a factor in the lack of complications. Additionally, we only evaluated patient safety and did not evaluate treatment outcome or efficacy. We are unable to determine whether the need for alternative treatment in the four patients was specifically due to the pedunculated fibroids as all four of those patients had additional fibroids which were also treated.

It is also important to realize that the designation of a subserosal leiomyoma as pedunculated is still problematic. This impacts reports regarding the treatment of pedunculated leiomyomas and may hamper comparison of studies from different institutions. While helpful, the UAE reporting standard definition of a stalk narrower than $50 \%$ of the diameter of the leiomyoma [14] ignores several issues. The definition does not specify whether a mean, minimum, or maximum diameter should be used for either the stalk or the leiomyoma. We are also unaware of empirical data that has evaluated the accuracy or reproducibility of stalk diameter measurement based on MR imaging. In our experience, it can sometimes be difficult to delineate the exact borders of the stalk. We are also unaware of any studies that have determined which MR pulse sequence best demonstrates the stalk.

\section{Conclusions}

Our preliminary experience found no evidence of complications specifically related to treatment of pedunculated subserosal uterine leiomyomas. While further experience with such patients will be informative, our findings suggest that pedunculated subserosal leiomyomas can be safely treated by MRgFUS ablation. Whether there is a specific stalk diameter or stalk diameter to leiomyoma diameter ratio that better defines treatment risk remains to be answered.

\section{Abbreviations}

FDA: Food and Drug Administration; MR: Magnetic resonance;

MRgFUS: Magnetic resonance-guided focused ultrasound ablation; NPV: Nonperfused volume; UAE: Uterine artery embolization.

\section{Competing interests}

The authors declare that they have no competing interests.

\section{Authors' contributions}

$\mathrm{DB}, \mathrm{GH}, \mathrm{KG}$, and $\mathrm{ES}$ were involved in the conception and design, analysis of data, and revising of the manuscript. All authors read and approved the final manuscript.

\section{Authors' information}

DB receives royalty from UpToDate and from Elsevier. GH participates in a $\mathrm{NIH} \mathrm{R01} \mathrm{grant} \mathrm{where} \mathrm{some} \mathrm{support} \mathrm{for} \mathrm{research} \mathrm{is} \mathrm{provided} \mathrm{by} \mathrm{Insightec.} \mathrm{GH}$ and KG receive support through RC1HD063312 and R01HD060503 from the Eunice Kennedy Shriver National Institute of Child Health and Human Development of the NIH. They also received salary support for a separate (unrelated to this study) clinical trial agreement between Mayo Clinic and InSightec (Haifa, Israel). ES is a clinical trial investigator at InSightec and $\mathrm{NIH}$ (HD063312 and HD060503), a consultant at Abbott, Bayer and Gynesonics, and a member of the scientific advisory board of Bayer Healthcare Foundation. She also receives royalties from UpToDate, Johns Hopkins University Press, Massachusetts Medical Society.

\section{Acknowledgements}

We thank Patty Johnson for her invaluable assistance as the Coordinator of our MRgFUS ablation practice for uterine leiomyomas, and for her help in maintaining the clinical database. We also thank Esther V.A. Bouwsma, MD for her assistance in data collection.

\section{Author details}

'Department of Radiology, Mayo Clinic, 200 First Street SW, Rochester, MN 55905, USA. ²Department of Obstetrics and Gynecology, Mayo Clinic, 200 First Street SW, Rochester, MN 55905, USA.

Received: 24 May 2013 Accepted: 20 August 2013

Published: 1 October 2013

\section{References}

1. Fennessy FM, Tempany CM, McDannold NJ, So MJ, Hesley G, Gostout B, Kim HS, Holland GA, Sarti DA, Hynynen K, Jolesz FA, Stewart EA. Uterine leiomyomas: MR imaging-guided focused ultrasound surgery-results of different treatment protocols. Radiology. 2007; 243:885-93.

2. Stewart EA, Gostout B, Rabinovici J, Kim HS, Regan L, Tempany CM. Sustained relief of leiomyoma symptoms by using focused ultrasound surgery. Obstet Gynecol. 2007; 110:279-87.

3. Taran FA, Tempany CM, Regan L, Inbar Y, Revel A, Stewart EA. Magnetic resonance-guided focused ultrasound (MRgFUS) compared with abdominal hysterectomy for treatment of uterine leiomyomas. Ultrasound Obstet Gynecol. 2009; 34:572-78.

4. Andrews RT, Spies JB, Sacks D, Worthington-Kirsch RL, Niedzwiecki GA Marx MV, Hovsepian DM, Miller DL, Siskin GP, Raabe RD, Goodwin SC, Min RJ, Bonn J, Cardella JF, Patel NH. Patient care and uterine artery embolization for leiomyomata. J Vasc Interv Radiol. 2004; 15:115-20. 
5. Braude P, Reidy J, Nott V, Taylor A, Forman R. Embolization of uterine leiomyomata: current concepts in management. Hum Reprod Update. 2000; 6:603-08.

6. Katsumori T, Akazawa K, Mihara T. Uterine artery embolization for pedunculated subserosal fibroids. AJR Am J Roentgenol. 2005; 184:399-402.

7. Margau R, Simons ME, Rajan DK, Hayeems EB, Sniderman KW, Tan K, Beecroft $J R$, Kachura JR. Outcomes after uterine artery embolization for pedunculated subserosal leiomyomas. J Vasc Interv Radiol. 2008; 19:657-61.

8. Smeets AJ, Nijenhuis RJ, Boekkooi PF, Vervest HA, van Rooij WJ, de Vries J, Lohle PN. Safety and effectiveness of uterine artery embolization in patients with pedunculated fibroids. J Vasc Interv Radiol. 2009; 20:1172-75.

9. Taran FA, Hesley GK, Gorny KR, Stewart EA. What factors currently limit magnetic resonance-guided focused ultrasound of leiomyomas? A survey conducted at the first international symposium devoted to clinical magnetic resonance-guided focused ultrasound. Fertil Steril. 2010; 94:331-34

10. Gorny KR, Hangiandreou NJ, Hesley GK, Gostout BS, McGee KP, Felmlee JP. MR guided focused ultrasound: technical acceptance measures for a clinical system. Phys Med Biol. 2006; 51:3155-73.

11. Gorny KR, Woodrum DA, Brown DL, Henrichsen TL, Weaver AL, Amrami KK, Hangiandreou NJ, Edmonson HA, Bouwsma EV, Stewart EA, Gostout BS, Ehman DA, Hesley GK. Magnetic resonance-guided focused ultrasound of uterine leiomyomas: review of a 12-month outcome of 130 clinical patients. J Vasc Interv Radiol. 2011; 22:857-64.

12. Hesley GK, Felmlee JP, Gebhart JB, Dunagan KT, Gorny KR, Kesler JB, Brandt $\mathrm{KR}$, Glantz JN, Gostout BS. Noninvasive treatment of uterine fibroids: early Mayo Clinic experience with magnetic resonance imaging-guided focused ultrasound. Mayo Clin Proc. 2006; 81:936-42.

13. Hesley GK, Gorny KR, Henrichsen TL, Woodrum DA, Brown DL. A clinical review of focused ultrasound ablation with magnetic resonance guidance: an option for treating uterine fibroids. Ultrasound $Q$. 2008; 24:131-39.

14. Goodwin SC, Bonilla SM, Sacks D, Reed RA, Spies JB, Landow WJ, Worthington-Kirsch RL. Reporting standards for uterine artery embolization for the treatment of uterine leiomyomata. J Vasc Interv Radiol. 2001; 12:1011-20.

15. Stewart EA, Rabinovici J, Tempany CM, Inbar $Y$, Regan $L$, Gostout $B$, Hesley G, Kim HS, Hengst S, Gedroyc WM. Clinical outcomes of focused ultrasound surgery for the treatment of uterine fibroids. Fertil Steril. 2006; 85:22-9.

16. Park H, Yoon S, Kim K, Kim DJ, Jung S. Magnetic resonsance imagingguided focused ultrasound treatment of pedunculated subserosal uterine fibroids: a preliminary report. J Vasc Interv Radiol. 2012: 23:1589-93.

doi:10.1186/2050-5736-1-19

Cite this article as: Brown et al:: Safety of MR-guided focused ultrasound treatment of pedunculated subserosal uterine leiomyomas. Journal of Therapeutic Ultrasound 2013 1:19.

\section{Submit your next manuscript to BioMed Central and take full advantage of:}

- Convenient online submission

- Thorough peer review

- No space constraints or color figure charges

- Immediate publication on acceptance

- Inclusion in PubMed, CAS, Scopus and Google Scholar

- Research which is freely available for redistribution

Submit your manuscript at www.biomedcentral.com/submit
C BioMed Central 